\title{
Polymer Film Blend of Polyvinyl Alcohol, Trichloroethylene and Cresol Red for Gamma Radiation Dosimetry
}

\author{
Aris Doyan ${ }^{1,2, *}$, Susilawati Susilawati ${ }^{1,2, *(\mathbb{D}}$, Saiful Prayogi ${ }^{3}$, Muhammad Roil Bilad ${ }^{3}{ }^{\circledR}$, Muhamad Fatikul Arif ${ }^{4}$ \\ and Noor Maizura Ismail ${ }^{5}$ (i) \\ 1 Science Education Program, University of Mataram, J1. Majapahit No. 62, Mataram 83125, Indonesia \\ 2 Physics Education, FKIP, University of Mataram, Jl. Majapahit No. 62, Mataram 83125, Indonesia \\ 3 Faculty of Applied Science and Enginering, Universitas Pendidikan Mandalika UNDIKMA, \\ Jl. Pemuda No. 59A, Mataram 83126, Indonesia; saifulprayogi@ikipmataram.ac.id (S.P.); \\ muhammadroilbilad@ikipmataram.ac.id (M.R.B.) \\ 4 Department of Materials Engineering, Institut Teknologi Sumatera, Lampung Selatan 35365, Indonesia; \\ mf.arif@mt.itera.ac.id \\ 5 Faculty of Engineering, Universiti Malaysia Sabah, Jln UMS, Kota Kinabalu 88400, Malaysia; \\ maizura@ums.edu.my \\ * Correspondence: aris_doyan@unram.ac.id (A.D.); susilawatihambali@unram.ac.id (S.S.)
}

Citation: Doyan, A.; Susilawati, S.; Prayogi, S.; Bilad, M.R.; Arif, M.F.; Ismail, N.M. Polymer Film Blend of Polyvinyl Alcohol, Trichloroethylene and Cresol Red for Gamma Radiation Dosimetry. Polymers 2021, 13, 1866. https://doi.org/10.3390/ polym 13111866

Academic Editor: Rodolphe Sonnier

Received: 30 March 2021

Accepted: 7 May 2021

Published: 4 June 2021

Publisher's Note: MDPI stays neutral with regard to jurisdictional claims in published maps and institutional affiliations.

Copyright: (c) 2021 by the authors. Licensee MDPI, Basel, Switzerland. This article is an open access article distributed under the terms and conditions of the Creative Commons Attribution (CC BY) license (https:/ / creativecommons.org/licenses/by/ $4.0 /)$.

\begin{abstract}
This study investigated the polymer film composite of polyvinyl alcohol (PVA), trichlorethylene (TCE) and cresol red (CR) dye irradiated with gamma $(\gamma)$ rays for potential application as radiation dosimetry. The film was prepared via the solvent-casting method with varying concentrations of TCE. Film samples were exposed to radiation from a $\gamma$-rays radiation source of ${ }^{60}$ Cobalt isotope. Color changes before and after $\gamma$-rays irradiation were observed, and the optical properties of the polymer films were investigated by spectrophotometry. Results show that increasing the radiation dose physically changed the color of the polymer film, from purple $(\mathrm{pH}>8.8)$ without radiation $(0 \mathrm{kGy})$ to yellow (almost transparent) $(2.8<\mathrm{pH}<7.2)$ at the highest dose $(12 \mathrm{kGy})$. The concentration of acid formed due to irradiation increased with the increase in irradiation doses and at higher TCE content. The critical doses of PVA-TCE composites decreased linearly with the increase of TCE composition, facilitating an easy calibration process. The dose response at $438 \mathrm{~nm}$ increased exponentially with increasing radiation dose, but showed an opposite trend at the $575 \mathrm{~nm}$ band. An increase in the TCA concentration indicated a decrease in the absorption edge and an increase in activation energy, but both decreased for all TCE concentrations at higher doses. The energy gap for the direct and the indirect transitions decreased with increasing TCE concentration and $\gamma$-rays radiation dose. The results of this study demonstrated the potential application of PVA-TCE-CR polymer film as $\gamma$-rays irradiation dosimetry in a useful dose range of $0-12 \mathrm{kGy}$.
\end{abstract}

Keywords: optical properties; polymer film composite; $\gamma$-rays irradiation; dosimetry

\section{Introduction}

Dosimeters from various materials have been intensively studied as devices to monitor radiation doses [1]. Dosimeters of colored thin-film polymer materials have been extensively developed for measuring the adsorbed radiation dose by materials, and have been applied in routine dosimeters [2]. The main technical advantage of a polymer film-based dosimeter as a radiation detector is its slightness and portability [3]. In addition, the film has a long storage stability, is sturdy, and is cost-effective [4]. Some of the applications of film dosimeters include: routine high-dose radiation to food and beverages [5]; sterilization process [6]; radiotherapy in medical field [7]; and dye dosimeters [8-10].

Radiation dosimetry is used to measure the absorbed radiation dose, or determine the incident radiation on a material [11]. Therefore, it is necessary to ensure the accuracy of the radiation dose $[12,13]$. Many materials have been developed and explored as radiation dosimetry, evaluated under different dose ranges [14-16]. A film-based radiation 
dosimetry can be developed from a mixture of polymers, with a dye as indicator. The polymer materials that have been explored include polyvinyl alcohol (PVA) [5,13]; polycarbonate [17]; polyvinyl chloride [18]; and polyvinyl butyric [14]. Meanwhile, coloring materials as indicators include: methylene blue and methylene red [4]; thymolphthalein (TP) [5]; ethyl violet and blue bromophenol [19]; cresol red (CR) [20]; tetrazolium violet [21]; and methyl viologen [22].

PVA based polymer materials are most recommended because they have a high degree of flexibility [23], are water-soluble [24], have good mechanical properties, and are non-toxic and elastic [25]. PVA has been combined with several mixed dyes (tetrabromo phenolphthalein ethyl ester, acid yellow, and chloral hydrate) and has shown promising prospect as a new dosimeter in the 0.1 to $5 \mathrm{kGy}$ dose range [1]. PVA with TP dye is effective as a new detector system for application at doses of 1 to $6.5 \mathrm{kGy}$ [5], and PVA with methyl thymol blue dye showed some efficacy under a dose range from 2.5 to $20 \mathrm{kGy}$ [11].

Several blends of chlorine-containing polymer have been investigated for possible use for dosimetry of $\gamma$-rays radiation and electron beams [26,27]. They also contain dye as $\mathrm{pH}$ indicators, and the presence of chlorine improves the water solubility. For instance, a mixture of dehydrochlorines and an acid has a low $\mathrm{pH}$. The low $\mathrm{pH}$ increases the sensitivity of the dye component to change color.

In this study, we explored the potential of PVA blended with trichlorethylene (TCE) and CR dye as a radiation dosimetry. The addition of a TCE that contains chlorine is expected to enhance the solubility and stabilize the $\mathrm{pH}$ [28], as well as increase the dye sensitivity [29]. TCE is also found to be an electro-catalyst in polymers [30]. In order to be applied as a radiation dosimetry, the optical properties of the PVA-TCE-CR polymer film need to be further explored. In this study, we investigated the optical characteristics of the PVA-TCE polymer film with CR dye, and irradiated with $\gamma$-rays at doses of 0 to $12 \mathrm{kGy}$. Several samples with TCE variations $(20 \%, 25 \%, 30 \%$, and $35 \%)$ were fabricated and characterized.

\section{Materials and Methods}

\subsection{Polymer Film Preparation}

Polymer film composites were prepared from the following components: PVA, TCE, $\mathrm{CR}$ dye, and color thinners (ethanol and $\mathrm{NaOH}$ ). The film from the mixture was prepared using the solvent-casting method [31]. A stock dye solution of the polymer film was prepared by mixing CR $0.08 \mathrm{~g}$ (SDS for 105225, Merck, Darmstadt, Germany) with $50 \mathrm{~mL}$ of ethanol (96\% technical, Merck, Darmstadt, Germany), and 10\% NaOH (Merck, Darmstadt, Germany). The mixture was then stirred for $10 \mathrm{~min}$ at room temperature until homogeneous. The prepared CR dye solution was placed in a closed container (bottle) at a room temperature of $25^{\circ} \mathrm{C}$ until further use.

The polymer film was prepared by dissolving $17.5 \mathrm{~g}$ PVA $(\mathrm{Mw}=72,000 \mathrm{~g} / \mathrm{mol}$, SigmaAldrich, St Louis, MO, USA) with $350 \mathrm{~mL}$ distilled water in a beaker. This mixture was heated at $80^{\circ} \mathrm{C}$ while stirring using a magnetic stirrer at $150 \mathrm{RPM}$ in an open container (to allow evaporation) for $4 \mathrm{~h}$ until the remaining volume of solution was $50 \mathrm{~mL}$. In this condition, TCE (Mw $=131.39 \mathrm{~g} / \mathrm{mol}$, Sigma-Aldrich, St Louis, MO, USA) was added to the mixture while stirring for $1 \mathrm{~h}$. The concentrations of TCE were varied at 20\%, 25\%,30\%, and $35 \%$. Afterward, the temperature was lowered to $25^{\circ} \mathrm{C}$, then the mixture was added to the stock CR dye solution. The mixture was then continuously stirred for about $20 \mathrm{~min}$ until homogeneous.

The homogeneous PVA-TCE-CR solution was poured onto a glass plate and spread evenly to form a thin film. The cast film was then left to stand for the drying process for $120 \mathrm{~h}$ at a room temperature of $25^{\circ} \mathrm{C}$. Under this condition, a solid polymer film was formed by a mixture of PVA-TCE-CR. After solidification, the polymer film was cut into a size of $2 \mathrm{~cm} \times 2 \mathrm{~cm}$ and stored in a special container ampoule to protect it from dirt and sun exposure, at room temperature. The average thickness of the resulting polymer films was $75 \pm 1 \mu \mathrm{m}$, measured using a digital micrometer (Mitutoyo Corporation, Kanagawa, Japan). 


\subsection{Polymer Film Irradiation}

The polymer film was irradiated with $\gamma$-rays (Gamma Irradiator ISG-500), sourced from ${ }^{60}$ Co pencil types (C-188 Cobalt-60 Sources, Nordion, Ottawa, ON, Canada) with an activity of $2 \times 250 \mathrm{kCi}$ and an average $\gamma$-energy of $1.25 \mathrm{MeV}$. The decay of a ${ }^{60} \mathrm{Co}$ nucleus releases one electron with $317.9 \mathrm{keV}$ energy and two $\gamma$ quanta with energies of $1.173 \mathrm{MeV}$ and 1.332 MeV. The films were irradiated with $1.25 \mathrm{MeV} \gamma$-rays from a J. L Sherpered type $\gamma$-ray $60 \mathrm{Co}$ source at a mean dose rate of $163.75 \mathrm{~Gy} \cdot \mathrm{min}^{-1}$. As such, the irradiation dosing rates were adjusted by manipulating the irradiation time. A total of 48 polymer film samples of four TCE concentrations $(20 \%, 25 \%, 30 \%$, and $35 \%)$ were irradiated under different doses of 1 to $12 \mathrm{kGy}$ at room temperature. As benchmarks, four samples of the polymer film were not irradiated ( $0 \mathrm{kGy})$ for each TCE concentration. The measurements were taken five times for each condition without any significant variations and presented as averages. The physical changes in the color of the film with or without irradiation were compared. From trial and error in the preliminary experiments, it was found that a small step of less than $1 \mathrm{kGy}$ was insignificant in changing the color of the films. A step of $1 \mathrm{kGy}$ was found significant and thus applied in the experiments. Moreover, these kinds of films are aimed to be used for sterilization applications that require up to $12 \mathrm{kGy}$.

\subsection{Optical Properties Analysis}

Measurement of the optical absorption of polymer films under all radiation doses and concentrations was done using a UV-Vis spectrophotometer (UV-1900i, WL range: 190-1100 nm, WA: + / 0.1-nm, Shimadzu, Canby, OR, USA). The scanning was done over a wavelength range of 300 to $700 \mathrm{~nm}$. The optical absorption characteristics were plotted in the form of a graph to show wavelength vs. absorbance relationships. Measurements were made on each film sample that had been irradiated by $\gamma$-rays with four variations of TCA concentrations $(20 \%, 25 \%, 30 \%$, and $35 \%)$. The formation of acid in film composites, critical dose at color change, optical absorption dose response, absorption edge $\left(A_{E}\right)$, activation energy $(\Delta E)$, and energy gap $(E g)$ were then evaluated. The absorption edge and activation energy were determined according to the Urbach edges method [32], and the optical energy gap was determined according to the Mott and Davis model [33].

\section{Results and Discussion}

\subsection{Discoloration of the Polymer Film before and after Radiation}

The color of the PVA-TCE-CR polymer film samples before and after $\gamma$-rays irradiation experienced significant changes as shown in Figure 1. Increasing the dose of $\gamma$-rays irradiation physically changed the color of the polymer film samples, from purple $(\mathrm{pH}>8.8)$ without radiation $(0 \mathrm{kGy})$ to yellow (leading to transparency) $(2.8<\mathrm{pH}<7.2)$ at the highest dose $(12 \mathrm{kGy})$. These findings show that exposure to $\gamma$-rays energy at different doses changed the color of the film, in which the dose played an important effect. The change of color was consistent for all variations of TCE concentrations. The decrease of the sample $\mathrm{pH}$ was caused by the presence of acids resulting from the interaction of $\gamma$-rays with water molecules and TCE.

The change in color can be ascribed to the decrease in the sample's $\mathrm{pH}$, caused by the presence of acid generated from the interaction of $\gamma$-rays with water molecules and TCE, a chlorine-containing substance. There was no color change for the dyed PVA films prepared without TCE added (for one concentration), even though it was irradiated to $12 \mathrm{kGy}$. This suggests that only TCE molecules of the PVA-TCE composites were affected by $\gamma$-rays irradiation within the applied dose range. Another study reported that the polymer film of PVA-chloral hydrate-TPBE-AY dyes irradiated by $\gamma$-rays produced colors from green to yellow to red, due to a decrease in $\mathrm{pH}$ that occurred due to $\mathrm{HCl}$ produced from chloral radiolysis [1]. 


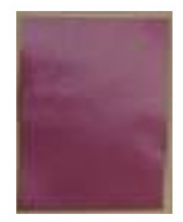

(a)

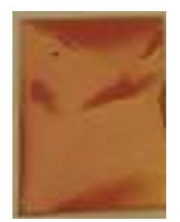

(b)

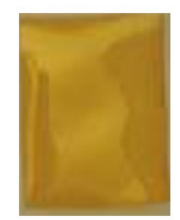

(c)

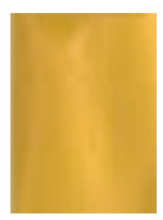

(d)

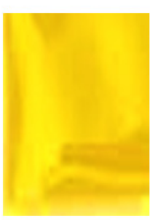

(e)

Figure 1. Appearance of the polymer film sample with $20 \%$ TCE after radiation with doses of (a) 0 kGy; (b) 2 kGy; (c) 4 kGy; (d) 6 kGy; and (e) 12 kGy.

The impact of irradiation on color changes found in this study is consistent with previous reports for different polymer film components. Previous studies showed that the blue color intensity of the polymer film mixture of methyl thymol blue and PVA decreased gradually with the increase in the $\gamma$-rays radiation dose. The color transition was attributed to the formation of a large number of free radicals due to radiation exposure, which gradually increased the rate of blue color reduction in the polymer film samples [11]. The $\gamma$-rays interactions produced hydrated electrons and free radicals that damage the dye material molecules and remove chromophores $[34,35]$. Increasing the radiation dose also led to a gradual bleaching of the polymer samples, as reported elsewhere [36]. In another report, the chlorine bonding of the mixed film polymer was dehydrochlorinated due to $\gamma$-rays irradiation, which increased the chlorine ion in the film [29].

\subsection{Absorption Spectra}

Figure 2 shows the absorption spectrum of the polymer blend film with TCE composition at $20 \%, 25 \%, 30 \%$ and $35 \%$. The absorption spectrum of the PVA-TCE-CR composites were measured before and after $\gamma$-irradiation with variable doses ( 0 to $12 \mathrm{kGy}$ ). Two absorption peaks at 438 and $575 \mathrm{~nm}$ bands were found to be consistent for all tested samples. A band at $575 \mathrm{~nm}$ served as the main absorbance peak of the purple color characteristic of the PVA-TCE-CR polymer film composite. At $20 \%$ TCE, films with a radiation dose of $0 \mathrm{kGy}$ (unirradiated) to the one irradiated with $9 \mathrm{kGy}$ maintained the main absorption peak at $575 \mathrm{~nm}$. However, the main absorbance peak of polymer films irradiated with 10,11 and $12 \mathrm{kGy}$ shifted from $575 \mathrm{~nm}$ to $438 \mathrm{~nm}$. The peak shifting for TCE concentration of $25 \%$, $30 \%$ and $35 \%$ occurred for irradiation doses of $9,10,11$ and 12; 8, 9, 10, 11 and 12; 7, 8, 9, 10, 11 and $12 \mathrm{kGy}$, respectively.

The absorption spectra of the unirradiated films show a main absorption peak at the $575 \mathrm{~nm}$ band (a characteristic of observed purple color). Upon irradiation, the absorbance at the $575 \mathrm{~nm}$ band decreased gradually, while at the absorption peak of the $438 \mathrm{~nm}$ band (a characteristic of observed yellow color) emerged with increasing intensity at higher doses.

These results are consistent with the results of previous studies on composite polymer film PVA-trichloroacetid acid (PVA-TCA) which produced the same absorption bands (575 nm and $438 \mathrm{~nm}$ ) as expected for most organic compounds containing chlorine [29]. However, they have a different dose response. For a given absorption dose, the absorbance of PVA-TCE composites in the $575 \mathrm{~nm}$ band was higher than that of the PVA-TCA composites, but for the $438 \mathrm{~nm}$ band, it was higher for the PVA-TCA composites than for the PVA-TCE composites. This difference within the literature data may be due to various factors, such as sample thickness, dose sensitivity, and the concentration of acid formed in the two sample systems.

The colorimetric property associated with the change in the optical absorption peak due to gamma radiation on a film is an important aspect in radiation dosimetry. In this study, we identified highly visible results within a 1 to $12 \mathrm{kGy}$ dose range that enable the polymer film materials to be used in many dosimetry applications using ${ }^{60} \mathrm{Co}$. At low doses $(<5 \mathrm{kGy})$, the film can be used as a dosimetry label or indicator for food irradiation processing, medical product sterilization, and polymer modification [1], while for high doses ( $>6 \mathrm{kGy}$ ), it can be applied to various control processes in industrial radiation facilities [13]. 


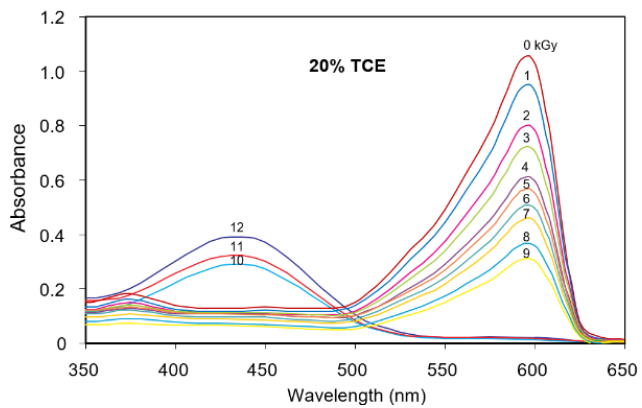

(a)

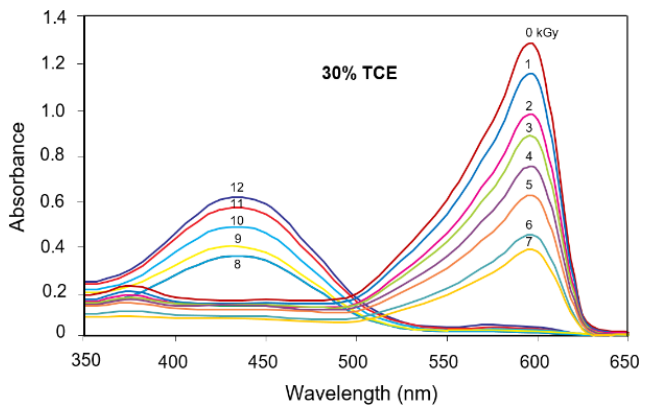

(c)

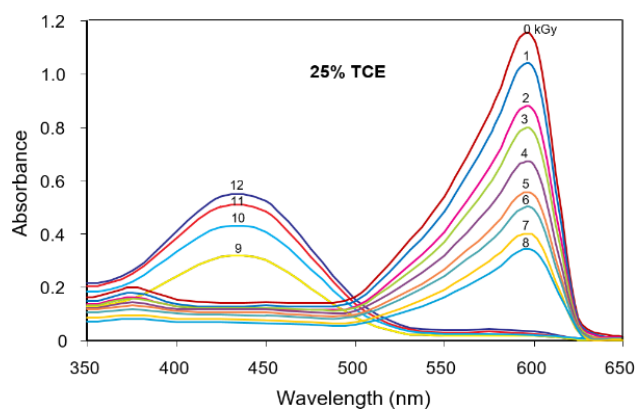

(b)

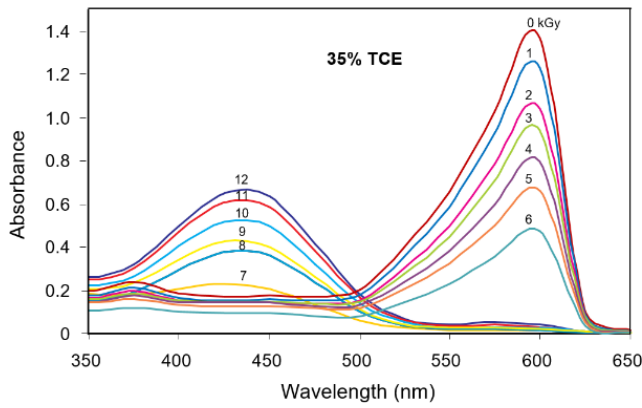

(d)

Figure 2. Absorbance spectra of CR dyed PVA-TCE composites containing; (a) 20\%; (b) 25\%; (c) 30\%; and (d) $35 \%$ TCE irradiated with $\gamma$-rays at various doses.

\subsection{Formation of Acid in PVA-TCE Composites}

Figure 3 shows the concentration of acid formed in the PVA-TCE samples containing different TCE compositions as a function of the absorbed dose. It could be seen that the concentration of acid formed increased with the increase in the irradiation dose and the TCE content. Upon irradiation, the TCE in the polymer film was dechlorinated, in which chlorine ions detached from the carbon backbone of TCE. Thus, the excited TCE dissociated to radicals, which may be represented by Equation (1).

$$
\mathrm{C}_{2} \mathrm{HCl}_{3} * \rightarrow \mathrm{C}_{2} \mathrm{H} \mathrm{Cl}_{2}+\dot{\mathrm{Cl}}
$$

The radicals of hydrogen $\mathrm{H}^{*}$ and hydroxyl $\mathrm{OH}^{*}$ from hydrolysis of water, and $\mathrm{Cl}^{*}$ from TCE recombined to form other chemical products including hydrochloric acid.

Figure 3 shows the concentration of acid formed in the PVA-TCE-CR polymer film composites during irradiation with $\gamma$-rays. It can be seen that the acid concentration was dependent on the dose and the composition and type of blend added. The acid formed increased with increasing TCE concentration from $20 \%$ to $35 \%$ and with the radiation dose up to $12 \mathrm{kGy}$.

Similar finding on acidification of irradiated polymer film were also reported in earlier studies. For a single carbon bond $(\mathrm{C}-\mathrm{C})$ containing compound in PVA-chloral hydrate composite, the acid concentration at dose $12 \mathrm{kGy}$ reached $1.0 \mathrm{~mol} \mathrm{~L}^{-1}$ for $34 \% \mathrm{CH}$ [37], while at the same radiation dose reached of $0.18 \mathrm{~mol} \mathrm{~L}^{-1}$ for $35 \%$ TCA (in PVA-composite) [29]. However, the acid formed in a double carbon bond $(\mathrm{C}=\mathrm{C})$ containing compound such as PVA-TCE composites, the acid formed was much smaller at $0.015 \mathrm{~mol} \mathrm{~L}^{-1}$ for $20 \%$ TCE and $0.022 \mathrm{~mol} \mathrm{~L}^{-1}$ for $35 \%$ TCE when irradiated at the dose $12 \mathrm{kGy}$. The increasing trend can be attributed to more energy of the photon required to break a covalent bond involving a $\mathrm{C}=\mathrm{C}$ compound. It follows that the amount of acid formed and the subsequent chemical and physical effects of irradiated PVA composites was influenced by the type of carbon bond of the compounds. 


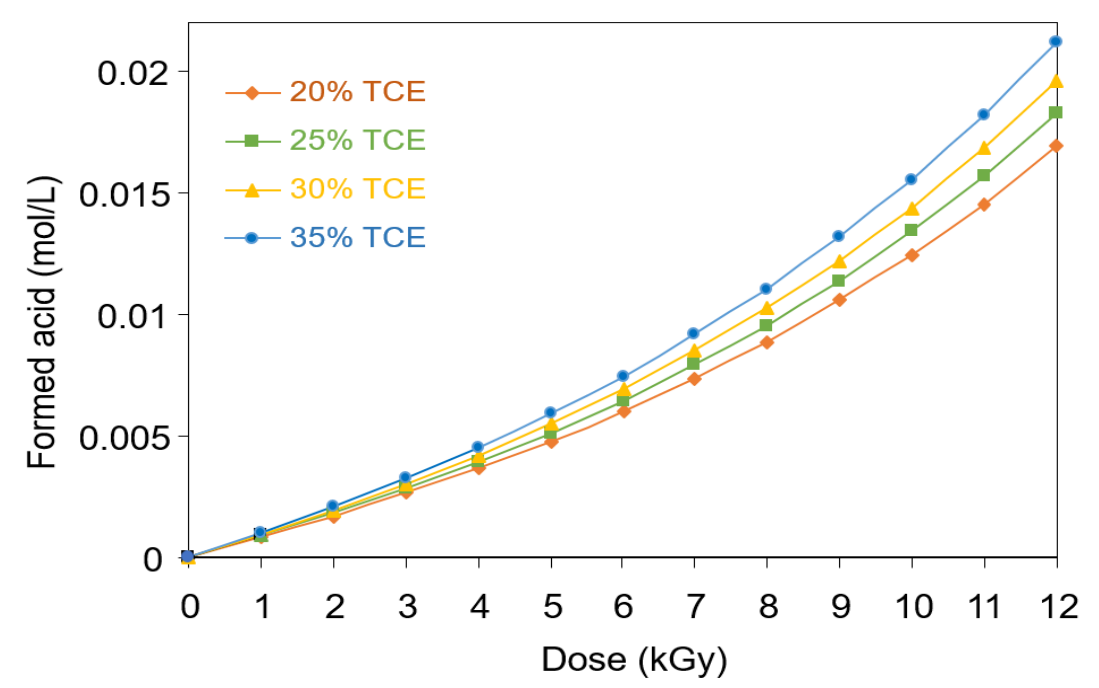

Figure 3. Concentration of acid formed as function of dose in PVA-TCE-CR polymer films with different compositions of TCE derived from the absorbance at $438 \mathrm{~nm}$.

\subsection{Critical Dose at Color Change}

The shift of the main absorption bands from $575 \mathrm{~nm}$ to $438 \mathrm{~nm}$ as the result of $\gamma$-rays irradiation on the film occurred at a certain dose point, called a critical dose, and has been shown in Figure 2. In Figure 4, the critical dose of each tested TCE concentration is presented by evaluating the intersection of absorption curves at $438 \mathrm{~nm}$ and $575 \mathrm{~nm}$ bands for each TCE composition. The dose at this intersection was taken as the critical dose $\left(D_{C}\right)$ at which the polymer film changed color from more purple/violet to more yellow (Figure 1). Figure 4 also shows the useful critical dose as a function of TCE composition. The values obtained from $20 \%, 25 \%, 30 \%$, and $35 \%$ of TCE were ranged at 8 to $9 \mathrm{kGy}, 7$ to $8 \mathrm{kGy}, 7 \mathrm{kGy}$, and $6 \mathrm{kGy}$, respectively.

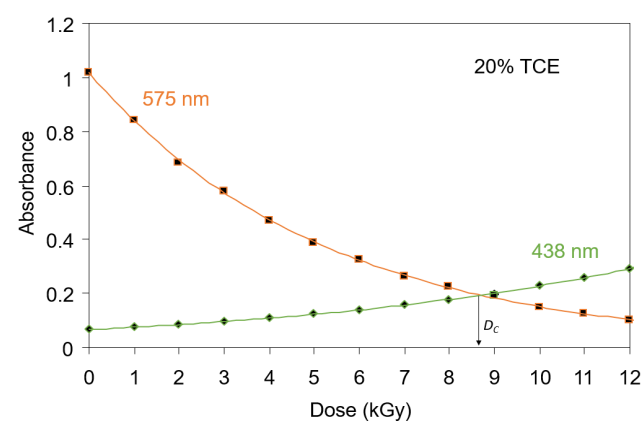

(a)

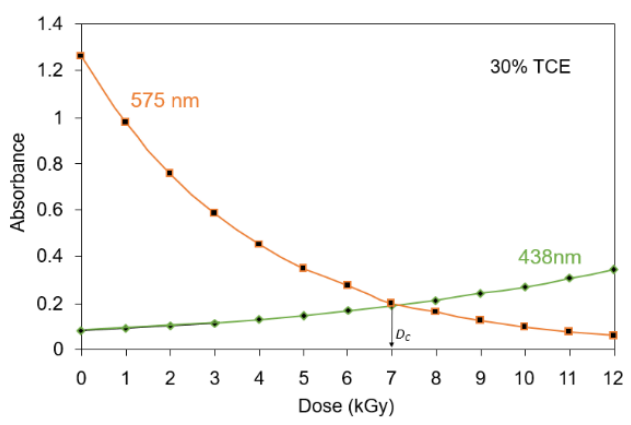

(c)

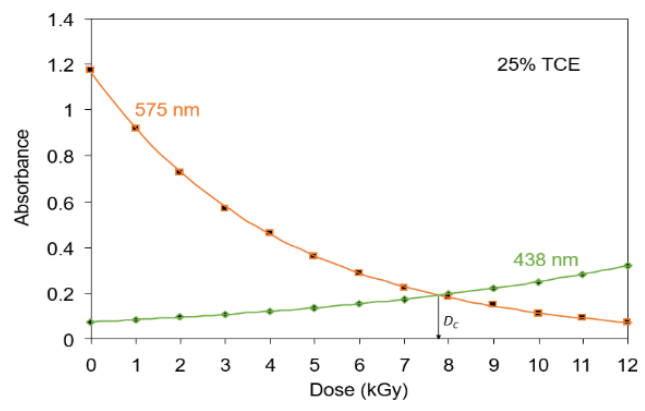

(b)

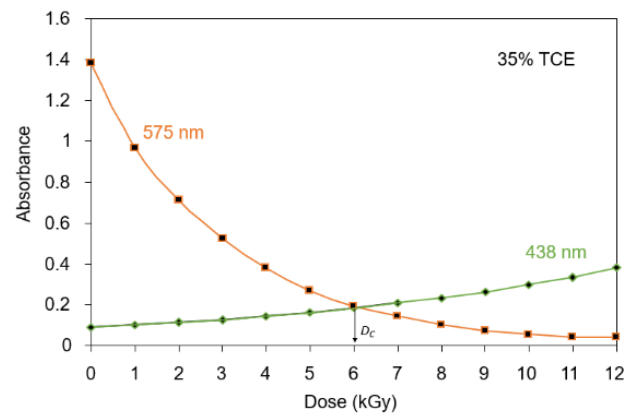

(d)

Figure 4. Critical doses determined as the intersection of absorbance at $575 \mathrm{~nm}$ and $438 \mathrm{~nm}$ bands for PVA-TCE-CR polymer film containing (a) 20\%, (b) 25\%, (c) 30\%, and (d) $35 \%$ TCE. 
Figure 5 shows critical doses as a function of TCE composition for PVA-TCE-CR polymer film. The critical dose decreased linearly with the increase of TCE composition and has a relationship given by $D_{C}=-0.18 C+12.35(\mathrm{r}=0.99)$, where $C$ is the composition of TCE. It shows that he critical dose of polymer film composites decreased linearly with increasing TCE compositions.

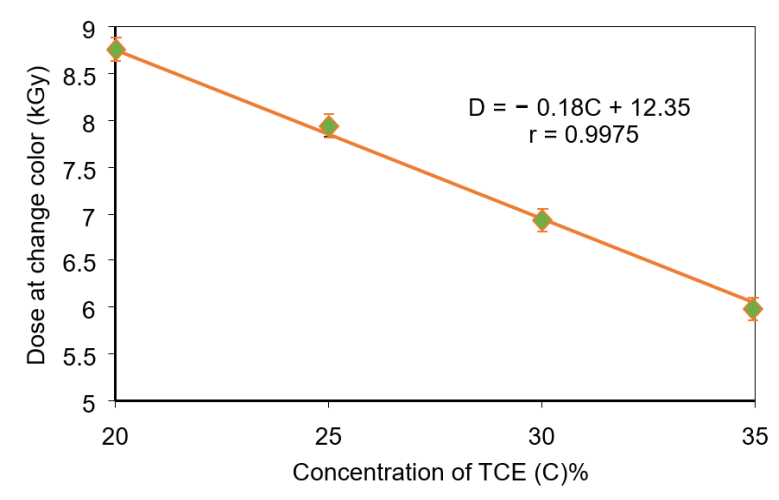

Figure 5. Useful critical doses as a function of TCE concentration for PVA-TCE-CR polymer films.

\subsection{Optical Absorption Dose Response}

The radiation dose response for each absorption band was evaluated as a function of the TCE content in the PVA-TCE-CR polymer films. The dose-response curves at $438 \mathrm{~nm}$ increased exponentially with doses as shown in Figure 6a. The data fitted well with a mathematical model of $y=y_{0} e^{D / D_{0}}$. The dose sensitivity parameter $D_{0}$ obtained had a function of $D_{0}=0.012 C+7.8311$, where $C$ is the composition of TCE, as shown in Figure 6b.

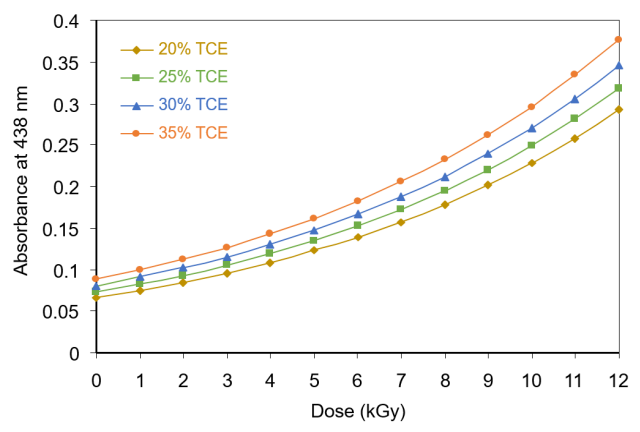

(a)

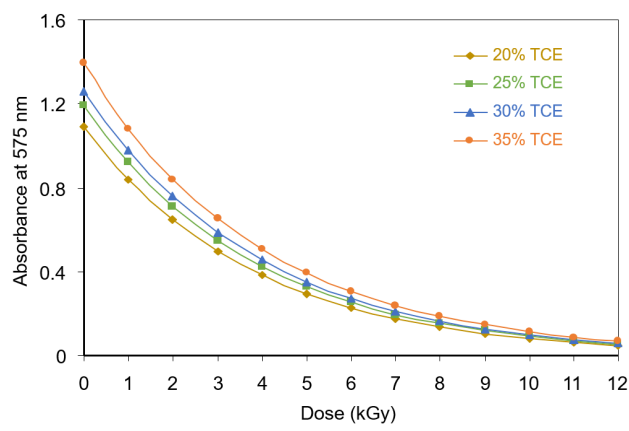

(c)

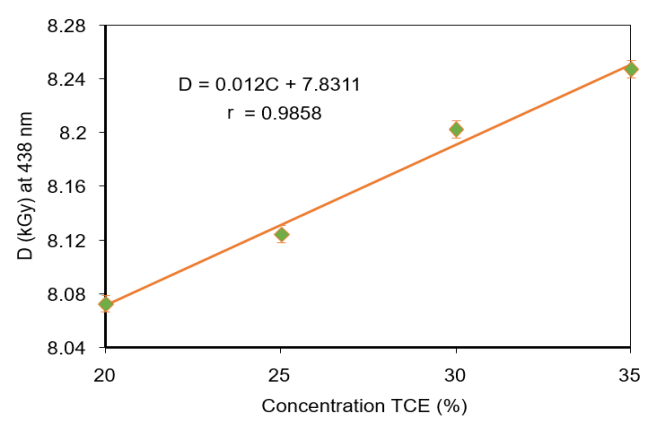

(b)

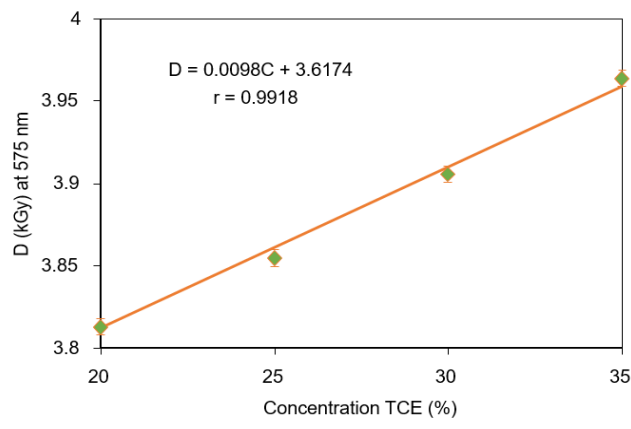

(d)

Figure 6. Optical absorption dose response; (a) dose response curve at $438 \mathrm{~nm}$ band; (b) sensitive dose $D_{0}$ vs. TCE composition as derived from $438 \mathrm{~nm}$ band; (c) dose response curve at $575 \mathrm{~nm}$ band; (d) sensitive dose $D_{0}$ as a function of TCE composition as derived from $575 \mathrm{~nm}$ band. 
For the dose-response curves at 575-nm band, which decreased exponentially with dose, a mathematical model of $y=y_{0} e^{-D / D_{0}}$ was used (Figure $6 \mathrm{c}$ ). The results show that $D_{0}$ had the relationship of $D_{0}=0.0098 \mathrm{C}+3.6174$, where $C$ is the composition of TCE, as shown in Figure 6d. Since, $D_{0}$ showed a linear relationship with the TCE composition, the dose response of the film is thus desirable for ease of calibration and interpretation as a radiation dosimetry.

\subsection{Absorption Edge}

The absorption of UV spectra increased with the increasing dose, as shown in Figure 7. This band corresponded to the excitation of outer electrons attributed to the $\pi-\pi *$ electronic transitions of electrons from donor atoms (HOMO) to acceptor atoms (LUMO) of the film. The absorption coefficient, $\alpha(v)$, of dyed PVA-TCE film was determined from the optical absorption spectrum. The plots of $\alpha(v)$ vs. $h v$ at different doses are shown in Figure 7 for different TCE compositions. Near the absorption edge, $\alpha$ increased more rapidly with $h v$. The absorption edge was determined by extrapolating the linear portions of $\alpha(v)$ vs. $h v$ curves to zero value of the absorption coefficient.

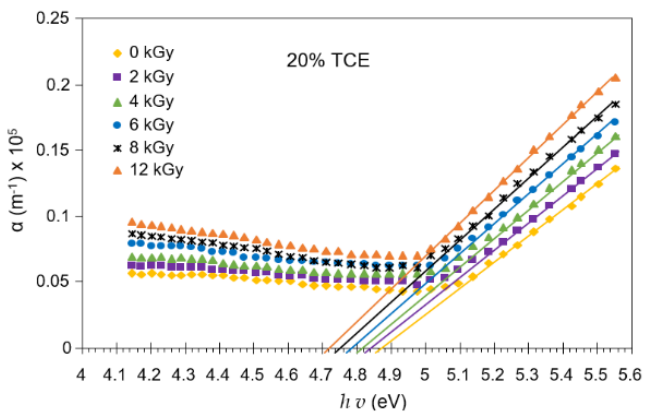

(a)

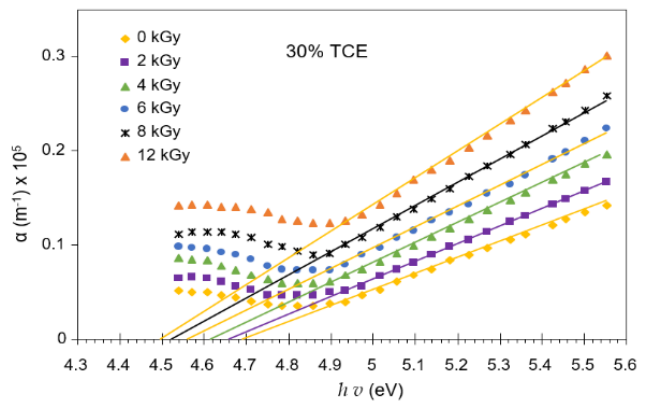

(c)

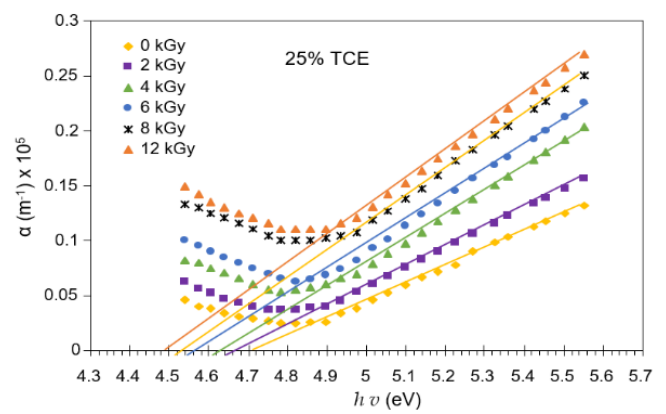

(b)

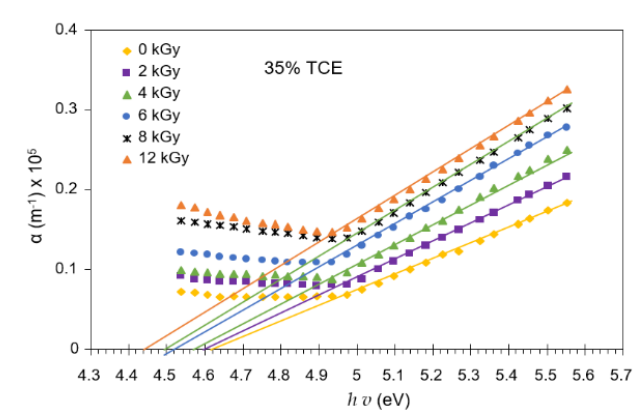

(d)

Figure 7. Relationship between $\alpha(v)$ vs. $h v$ under different doses for; (a) $20 \%$; (b) $25 \%$; (c) $30 \%$; and (d) $35 \%$ of TCE content in PVA-TCE-CR polymer film.

The absorption edge decreased with increasing TCE composition and increasing dose as shown in Figure 8. The absorption edge of dyed PVA-TCE film decreased for $20 \%$ TCE from 4.88 to $4.72 \mathrm{eV}$ when the dose increased from 0 to $12 \mathrm{kGy}$. For the same radiation condition, it decreases from 4.63 to $4.44 \mathrm{eV}$ for 35\% TCE. When compared with literature data, at about the same blend composition, the absorption edge of the PVA-CH film was higher than that the PVA-TCE film [37], followed by the PVA-TCA film [29]. Overall, the absorption edge of irradiated PVA-TCE composites was higher than that of the UPVC (4.35 to $2.04 \mathrm{eV}$ ) [38]. 


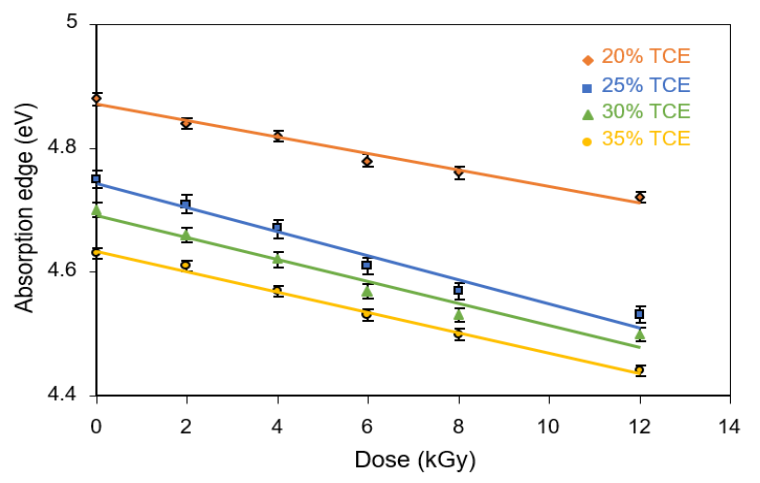

Figure 8. Absorption edge of PVA-TCE-CR polymer films as a function of dose for different TCE compositions.

For pure PVA film, the absorption edge was found to be around $5.34 \mathrm{eV}$ [39]. In the present study, this value was reduced by $0.9 \mathrm{eV}$, under 35\% PVA-TCE and a dose of $12 \mathrm{kGy}$ to about $4.44 \mathrm{eV}$. A greater trend of decreasing absorption edge with increasing radiation dose was also found in polymer films blended with salts, such as $\mathrm{PVA}-\mathrm{AgNO}_{3}$ polymer film irradiated with $\gamma$-rays at high doses. At doses of 20 to $50 \mathrm{kGy}$, it produced an absorption edge of 1.43. to $0.96 \mathrm{eV}$ [40].

\subsection{Activation Energy}

The optical activation energy was evaluated using the Urbach edges method [32]. The activation energy of irradiated samples was determined from the slope of the straight line of $\ln (\alpha)$ versus photon energy $h v$ for different TCE compositions (Figure 9). The activation energy in a reaction is defined as the amount of energy required to start a reaction. This represents the minimum energy required to form a complex motion in the event of a collision between reagents [41].

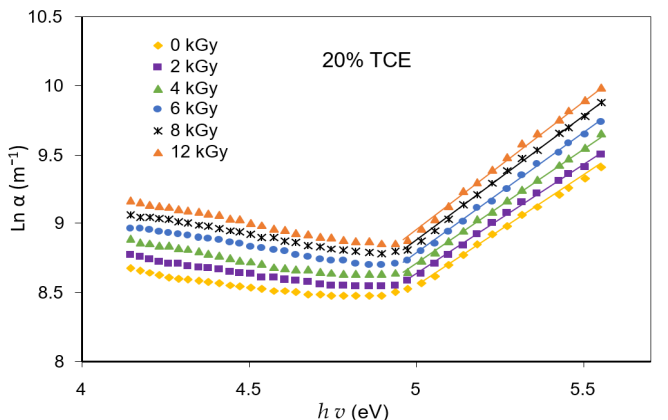

(a)

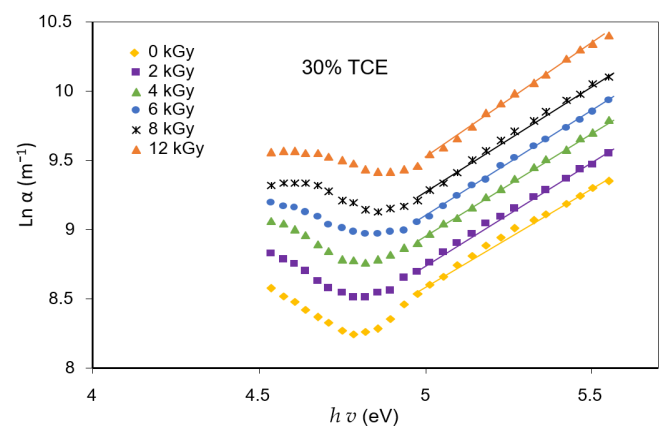

(c)

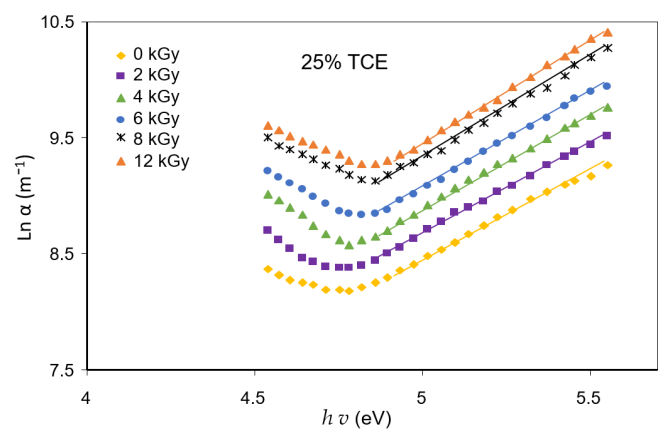

(b)

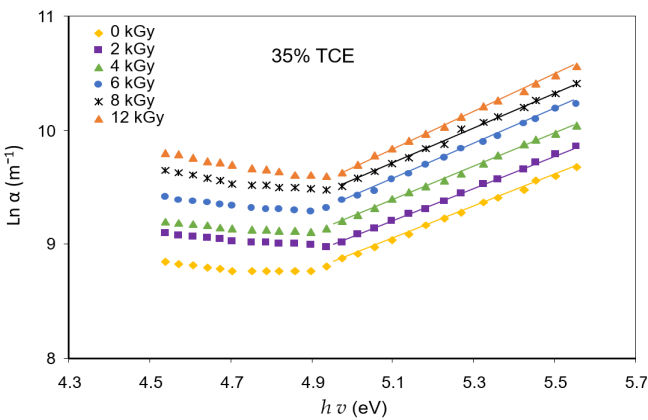

(d)

Figure 9. Variation of $\ln (\alpha)$ vs. h $v$ at various doses for; (a) $20 \%$; (b) $25 \%$; (c) $30 \%$; and (d) $35 \%$ TCE composition of CR dyed PVA-TCE composites. 
From the results shown in Figure 10, it can be seen that activation energy decreased with the increase of the radiation dose as well as TCE concentration. It was found that the activation energy value at $0 \mathrm{~Gy}$ increased from $0.66 \mathrm{eV}$ for the $20 \%$ TCE to $0.72 \mathrm{eV}$ for the $35 \%$ TCE. At $12 \mathrm{kGy}$, the value increases from $0.49 \mathrm{eV}$ for the $20 \% \mathrm{TCE}$ to $0.65 \mathrm{eV}$ for the $35 \%$ TCE. Therefore, activation energy increased with the increase of the TCE composition and decreased at higher doses. These findings are supported by the results of previous studies, that the activation energy decreased with an increasing dose of $\gamma$-rays irradiation [29] as a result of chain-scission polymeric molecules in polymer samples [42]. Evaluation of previous studies revealed that activation energy values of PVA-TCE composites were higher than that of PVA-TCA composites for all tested compositions and doses [29]. This finding suggests that radiation dose affected significantly the change of the width of the tail of the localized states of the energy band.

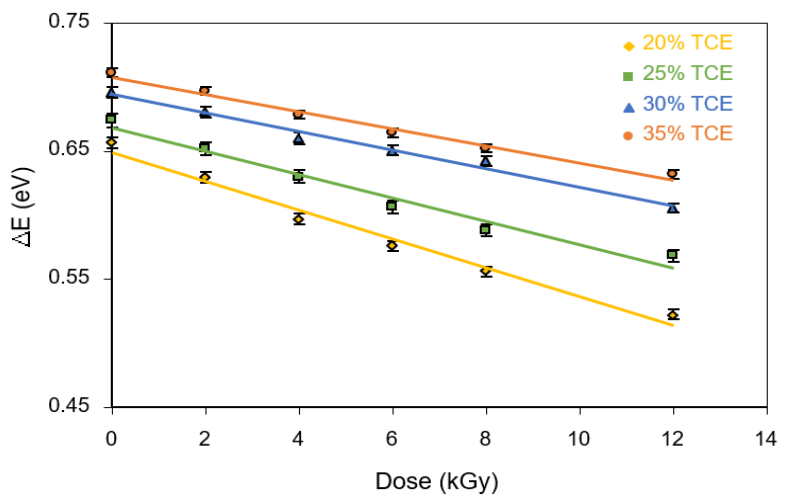

Figure 10. Effect of $\gamma$-rays irradiation and TCE composition on the optical activation energy $(\Delta E)$ of CR dyed PVA-TCE composites.

\subsection{Band Gap Energy}

Figure 11 shows extrapolation $(\alpha \mathrm{h} v)^{\mathrm{m}}$ versus $\mathrm{h} v$ that resulted in a variation energy gap for each radiation dose and concentration. The energy gap was determined according to the Mott and Davis model [33]. Band gap energy or energy gap is the energy range in the absence of electrons from a material; it lies between the valence and conduction bands [43]. Enough energy is required to make the transition of these two bands [44]. Optical absorption spectrum analysis can be used to determine the optical energy gap between the valence band and the conduction band due to direct and indirect transitions $[45,46]$. The direct optical band gaps in UV region were evaluated from $(\alpha h v)^{2}$ versus $h v$ at different doses, as illustrated in Figure 11.

Figure 12 summarizes the relationship between the optical band gaps and dose at different TCE compositions. The results show that the direct energy gap decreased with increasing doses for all TCE compositions. It was found that the energy gap at 0 Gy decreased from $5.21 \mathrm{eV}$ for the $20 \%$ TCE to $5.07 \mathrm{eV}$ for the $35 \%$ TCE. At $12 \mathrm{kGy}$, the value decreased from $5.04 \mathrm{eV}$ for the 20\% TCE to $4.90 \mathrm{eV}$ for the $35 \%$ TCE. The energy gap value of the PVA-TCE film was slightly smaller than that of the PVA-TCA films under all doses [29].

The indirect optical band gap energy of the UV region was evaluated from the linear plots of $(\alpha h v)^{1 / 2}$ vs. $h v$ under different doses, as illustrated in Figure 13. The extrapolation, for which $(\alpha h v)^{1 / 2}=0$ yielded the indirect optical band gap, was a function of the dose, as illustrated in Figure 14. The indirect band gap decreased with the increase in dose for all TCE compositions. It had similar features to that of the direct band gap, but the value of the indirect band gap energy was always smaller. It was found that at $0 \mathrm{~Gy}$, the indirect energy gap decreased from $4.96 \mathrm{eV}$ for the $20 \%$ TCE to $4.62 \mathrm{eV}$ for the $35 \%$ TCE. At $12 \mathrm{kGy}$, the value decreased from $4.74 \mathrm{eV}$ for the $20 \%$ TCE to $4.23 \mathrm{eV}$ for the $35 \%$ TCE. It was found also that the indirect band gaps of the PVA-TCE composites were larger than that of the PVA-TCA composites [29], for the same compositions and doses. The decrease in the band 
gap resulted from the increase in polarons and free ions in the polymer sample, due to exposure to the $\gamma$-rays irradiation, as explained elsewhere [44,47].

Overall, these results suggest that the amount of energy gap in the irradiated polymer material depends on the type and composition of the dopants under the influence of $\gamma$-ray irradiation. The response of the optical properties of the material to the radiation dose is very important to be investigated. The results of previous studies showed a linear response of decreasing energy gaps to $\gamma$-rays irradiation on $\mathrm{TeO}_{2}$ thin films observed in the dose

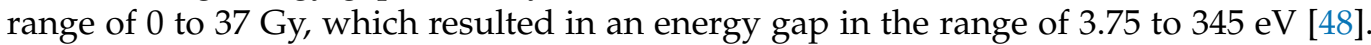
The linear response decreased the energy gap to 4.16 and $4.34 \mathrm{eV}$ for $\mathrm{KCl}-\mathrm{Mn}$ and $\mathrm{KCl}-\mathrm{Ce}$ phosphorus polymer materials irradiated with $\gamma$-rays at doses of 0.08 to $0.75 \mathrm{kGy}$ [49].

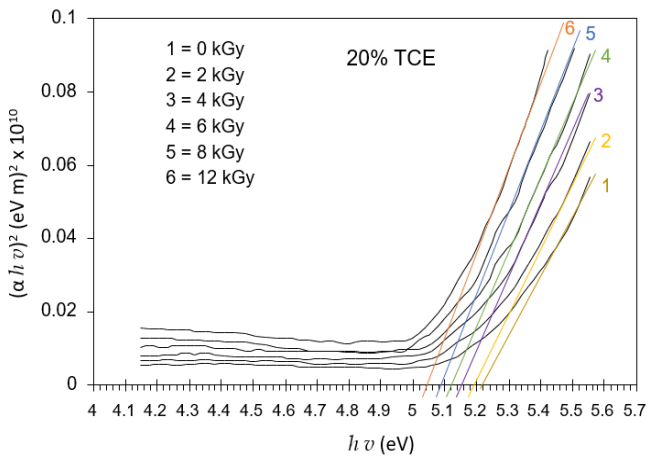

(a)

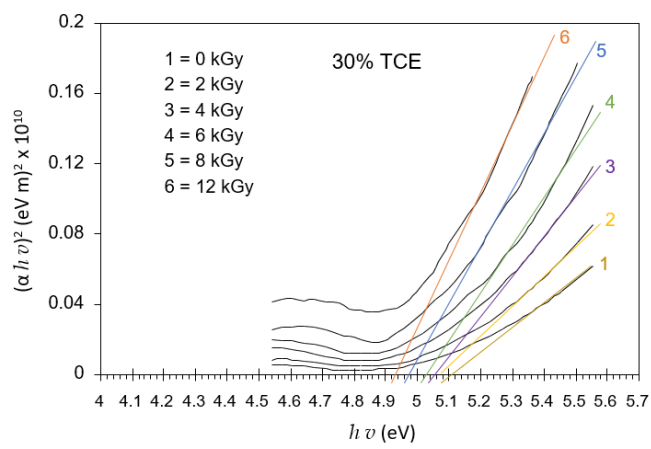

(c)

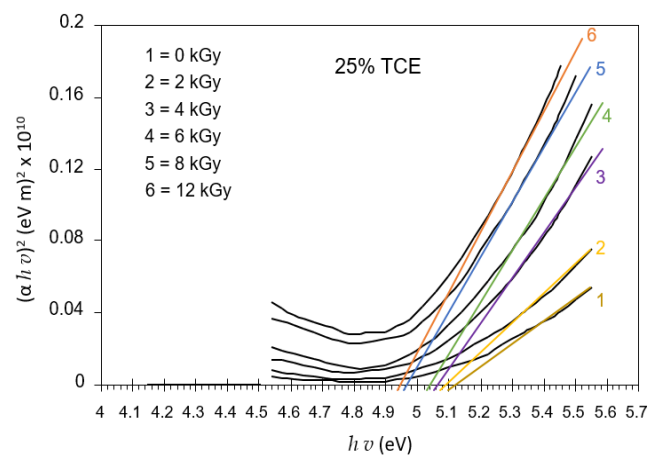

(b)

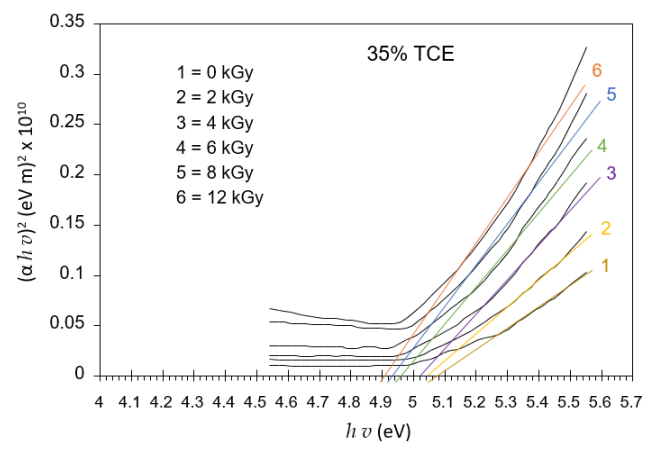

(d)

Figure 11. Variation of direct allowed transition $(\alpha h v)^{2}$ vs. $h v$ at various doses for PVA-TCE-CR polymer film at; (a) 20\%; (b) 25\%; (c) 30\%; and (d) 35\% TCE composition.

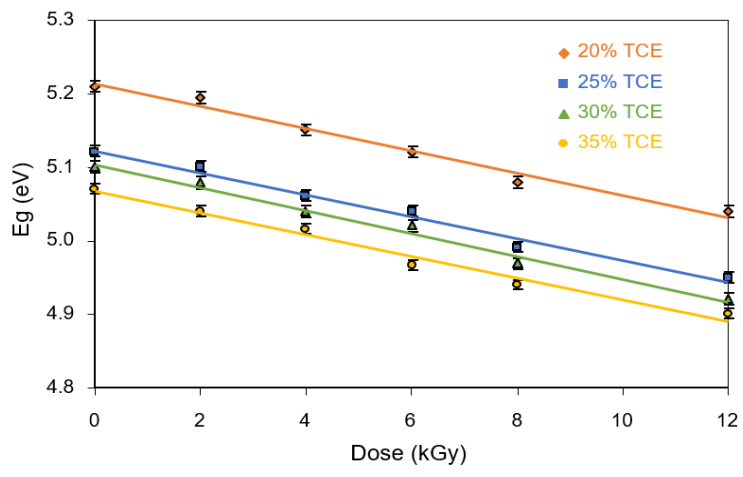

Figure 12. Variation of the direct energy band gaps with dose for PVA-TCE-CT polymer films at different TCE compositions. 


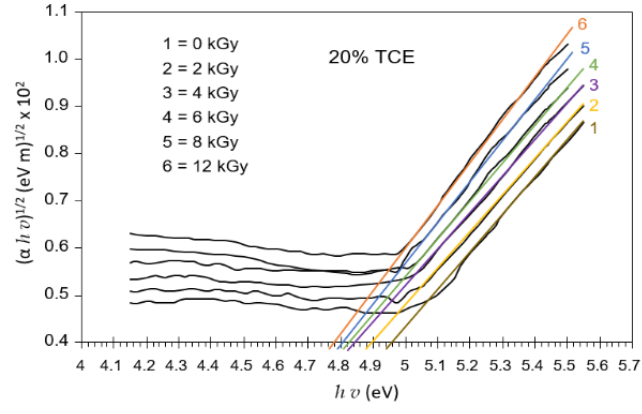

(a)

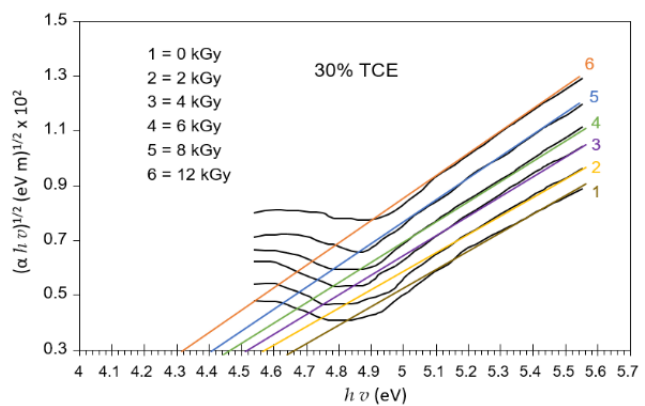

(c)

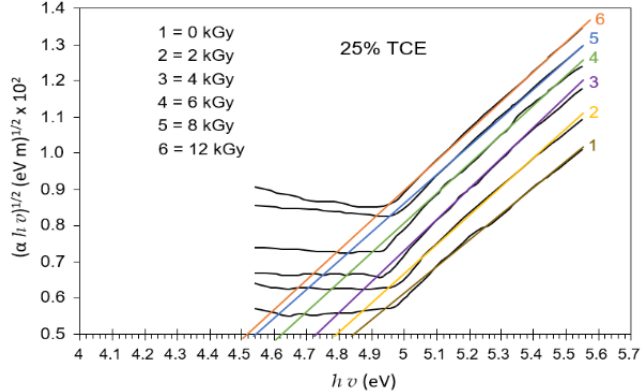

(b)

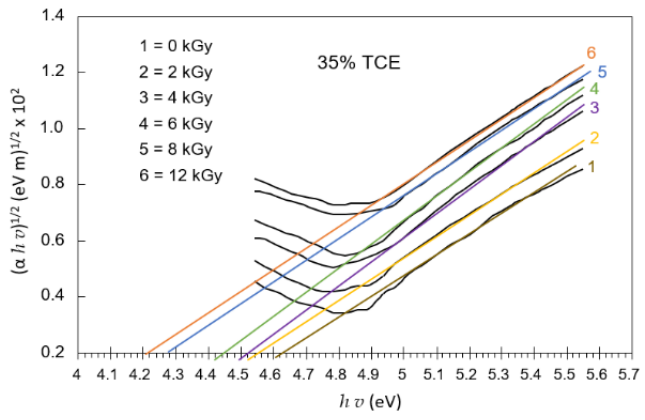

(d)

Figure 13. Variation of indirect allowed transition $(\alpha h v)^{1 / 2}$ vs. $h v$ at various doses PVA-TCE-CT polymer films at; (a) 20\%; (b) 25\%; (c) 30\%; and (d) 35\% TCE composition.

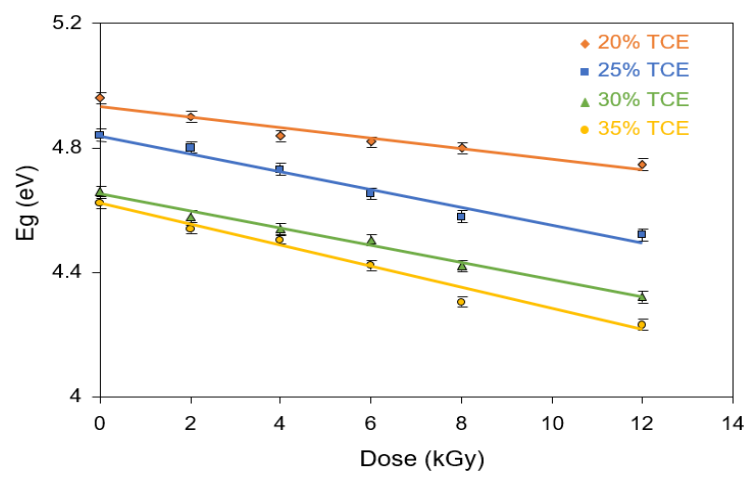

Figure 14. Variation of the indirect energy band gaps with dose for CR dyed PVA-TCE films at different TCE compositions.

The behavior of the optical properties of the studied material specimens under the influence of radiation dose is important to identify its potential application in radiation dosimetry systems. They usually show varying responses to the dose exposed to the material, such as linear, supralinear, saturated response, and defective with increasing radiation dose [50]. In this present work, the energy gap for both types of transitions (direct and indirect) showed a linear decreasing response to radiation dose. Linearity indicated that the material has stable optical properties which can be used as a promising dosimetry [48,49].

\section{Conclusions}

The PVA-TCE-CR polymer film composite has been introduced for $\gamma$-rays irradiation dosimetry applications. The study of its optical properties was explored before and after $\gamma$-rays irradiation. Results showed that increasing the radiation dose physically changed the color of the polymer film, from purple $(\mathrm{pH}>8.8)$ without radiation $(0 \mathrm{kGy})$ to yellow 
(almost transparent) $(2.8<\mathrm{pH}<7.2)$ at the highest dose $(12 \mathrm{kGy})$, demonstrating its effective use as dosimetry. The concentration of acid formed increased at a higher dosing rate and composition of TCE, which affected the color transition of the irradiated films. The critical doses of film composites decreased linearly with the increase of TCE compositions. The dose response at $438 \mathrm{~nm}$ increased exponentially with increasing radiation doses. Conversely, the dose response at the $575 \mathrm{~nm}$ band decreased with increasing radiation doses. An increase in the TCA concentration indicated a decrease in the absorption edge and an increase in activation energy, but both decreased for all TCE concentrations at higher doses. The energy gap for the direct and the indirect transitions decreased with increasing TCE concentration and $\gamma$-rays radiation dose. The results of this study indicated the potential application of PVA-TCE-CR polymer film as $\gamma$-rays irradiation dosimetry in a useful dose range of $0-12 \mathrm{kGy}$. We have identified highly visible results within a 1 to $12 \mathrm{kGy}$ dose range, allowing the PVA-TCE-CR based polymer film composite to be applied in many dosimetry applications using ${ }^{60} \mathrm{CO}$. At doses of $<5 \mathrm{kGy}$, it is applicable as a dosimetry label or indicator for food irradiation processing and polymer modification, while for doses of $>6 \mathrm{kGy}$, it can be applied to medical product sterilization and various control processes in radiation facilities.

Author Contributions: Conceptualization, A.D.; methodology, A.D.; formal analysis, S.S., N.M.I. and M.F.A.; investigation, A.D. and S.S.; resources, A.D. and S.S.; data curation, S.P.; writing-original draft preparation, A.D.; writing—review and editing, S.P., M.F.A., N.M.I. and M.R.B.; visualization, S.P. All authors have read and agreed to the published version of the manuscript.

Funding: This research received no external funding.

Institutional Review Board Statement: Not applicable.

Informed Consent Statement: Not applicable.

Data Availability Statement: The data presented in this study are available on request from the corresponding author.

Conflicts of Interest: The authors declare no conflict of interest.

\section{References}

1. Gafar, S.M.; El-Kelany, M.; El-Ahdal, M. Low-Dose Film Dosimeter Based on Mixture of AY and TBPE Dyed Poly(Vinyl Alcohol). Dyes Pigment. 2017, 140, 1-5. [CrossRef]

2. Kattan, M.; al Kassiri, H.; Daher, Y. Using Polyvinyl Chloride Dyed with Bromocresol Purple in Radiation Dosimetry. Appl. Radiat. Isot. 2011, 69, 377-380. [CrossRef]

3. Akhtar, S.; Shahzad, A.; Bashir, S.; Hussain, M.Y.; Akhtar, N. Improved Performance of Radiochromic Films for High-Dose Dosimetry. Radioprotection 2016, 51, 129-133. [CrossRef]

4. Akhtar, S.; Hussain, T.; Shahzad, A.; Qamar-ul-Islam. The Feasibility of Reactive Dye in PVA Films as High Dosimeter. J. Basic Appl. Sci. 2013, 9, 420-423. [CrossRef]

5. El-Kelany, M.; Gafar, S.M. Preparation of Radiation Monitoring Labels to $\gamma$ Ray. Optik 2016, 127, 6746-6753. [CrossRef]

6. Gafar, S.M.; El-Ahdal, M.A. Dosimetric Characteristics of 2,6 Di-Nitro Phenol for High Dose Dosimetry. Dyes Pigment. 2014, 109, 67-71. [CrossRef]

7. Hassani, H.; Nedaie, H.A.; Zahmatkesh, M.H.; Shirani, K. A Dosimetric Study of Small Photon Fields Using Polymer Gel and Gafchromic EBT Films. Med. Dosim. 2014, 39, 102-107. [CrossRef] [PubMed]

8. Ali-Omer, M.A.; Ali-Bashir, E.A. Synthesis of Polyvinyl Alcohol and Cuprous Oxide (PVA/Cu 2 O) Films for Radiation Detection and Personal Dosimeter Based on Optical Properties. J. Radiat. Res. Appl. Sci. 2018, 11, 237-241. [CrossRef]

9. Aydarous, A.; Badawi, A.; Abdallah, S. The Effects of Electrons and Photons Irradiation on the Optical and Thermophysical Properties of Gafchromic HD-V2 Films. Results Phys. 2016, 6, 952-956. [CrossRef]

10. Basfar, A.A.; Rabaeh, K.A.; Mousa, A.A. Improved Performance of Nitro-Blue Tetrazolium Polyvinyl Butyral High Dose Film Dosimeters. Radiat. Meas. 2012, 47, 1005-1008. [CrossRef]

11. Rabaeh, K.A.; Aljammal, S.A.; Eyadeh, M.M.; Abumurad, K.M. Methyl Thymol Blue Solution and Film Dosimeter for High Dose Measurements. Results Phys. 2021, 23, 103980. [CrossRef]

12. Hosni, F.; Farah, K.; Kaouach, H.; Louati, A.; Chtourou, R.; Hamzaoui, A.H. Effect of Gamma-Irradiation on the Colorimetric Properties of Epoxy-Resin Films: Potential Use in Dosimetric Application. Nucl. Instrum. Methods Phys. Res. Sect. B Beam Interact. Mater. At. 2013, 311, 1-4. [CrossRef] 
13. Raouafi, A.; Daoudi, M.; Jouini, K.; Charradi, K.; Hamzaoui, A.H.; Blaise, P.; Farah, K.; Hosni, F. Effect of Gamma Irradiation on the Color, Structure and Morphology of Nickel-Doped Polyvinyl Alcohol Films: Alternative Use as Dosimeter or Irradiation Indicator. Nucl. Instrum. Methods Phys. Res. Sect. B Beam Interact. Mater. At. 2018, 425, 4-10. [CrossRef]

14. Abdel-Fattah, A.A.; Soliman, Y.S.; Bayomi, A.M.M.; Abdel-Khalek, A.A. Dosimetric Characteristics of a Radiochromic Polyvinyl Butyral Film Containing 2,4-Hexadiyn-1,6-Bis(n-Butyl Urethane). Appl. Radiat. Isot. 2014, 86, 21-27. [CrossRef]

15. Soliman, Y.S.; Abdel-Fattah, A.A.; Alkhuraiji, T.S. Radiochromic Film Containing Poly(Hexa-2,4-Diynylene Adipate) as a Radiation Dosimeter. Appl. Radiat. Isot. 2018, 141, 80-87. [CrossRef] [PubMed]

16. Ticoş, D.; Scurtu, A.; Oane, M.; Diplaşu, C.; Giubega, G.; Călina, I.; Ticoş, C.M. Complementary Dosimetry for a 6 MeV Electron Beam. Results Phys. 2019, 14, 102377. [CrossRef]

17. Galante, A.M.S.; Campos, L.L. Mapping Radiation Fields in Containers for Industrial $\gamma$-Irradiation Using Polycarbonate Dosimeters. Appl. Radiat. Isot. 2012, 70, 1264-1266. [CrossRef]

18. Kattan, M.; Daher, Y. The Use of Polyvinyl Chloride Films Dyed with Methyl Red in Radiation Dosimetry. IJRR 2016, 14, $263-267$. [CrossRef]

19. Ebraheem, S.; El-Kelany, M. Dosimeter Film Based on Ethyl Violet-Bromophenol Blue Dyed Poly(Vinyl Alcohol). OJPChem 2013, 3, 1-5. [CrossRef]

20. Ebraheem, S.; Eid, S.; Kovacs, A. A New Dyed Poly (Vinyl Alcohol) Film for High-Dose Applications. Radiat. Phys. Chem. 2002, 63, 807-811. [CrossRef]

21. Emi-Reynolds, G.; Kovacs, A.; Fletcher, J.J. Dosimetry Characterization of Tetrazolium Violet-Polyvinylalcohol Films. Radiat. Phys. Chem. 2007, 76, 1519-1522. [CrossRef]

22. Lavalle, M.; Corda, U.; Fuochi, P.G.; Caminati, S.; Venturi, M.; Kovács, A.; Baranyai, M.; Sáfrány, A.; Miller, A. Radiochromic Film Containing Methyl Viologen for Radiation Dosimetry. Radiat. Phys. Chem. 2007, 76, 1502-1506. [CrossRef]

23. Ang, S.L.; Sivashankari, R.; Shaharuddin, B.; Chuah, J.-A.; Tsuge, T.; Abe, H.; Sudesh, K. Potential Applications of Polyhydroxyalkanoates as a Biomaterial for the Aging Population. Polym. Degrad. Stab. 2020, 181, 109371. [CrossRef]

24. Wong, C.Y.; Wong, W.Y.; Loh, K.S.; Daud, W.R.W.; Lim, K.L.; Khalid, M.; Walvekar, R. Development of Poly(Vinyl Alcohol)-Based Polymers as Proton Exchange Membranes and Challenges in Fuel Cell Application: A Review. Polym. Rev. 2020, 60, 171-202. [CrossRef]

25. Chaturvedi, A.; Bajpai, A.K.; Bajpai, J.; Sharma, A. Antimicrobial Poly(Vinyl Alcohol) Cryogel-Copper Nanocomposites for Possible Applications in Biomedical Fields. Des. Monomers Polym. 2015, 18, 385-400. [CrossRef]

26. Abdel-Fattah, A.A.; El-Kelany, M.; Abdel-Rehim, F. Development of a Radiation-Sensitive Indicator. Radiat. Phys. Chem. 1996, 48, 497-503. [CrossRef]

27. Abdel-Fattah, A.A.; El-Kelany, M.; Abdel-Rehim, F.; El Miligy, A.A. UV-Sensitive Indicators Based on Bromophenol Blue and Chloral Hydrate Dyed Poly(Vinyl Butyral). J. Photochem. Photobiol. A Chem. 1997, 110, 291-297. [CrossRef]

28. Nayef, U.M.; Khudhair, I.M. Study of Porous Silicon Humidity Sensor Vapors by Photoluminescence Quenching for Organic Solvents. Optik 2017, 135, 169-173. [CrossRef]

29. Susilawati, U.; Doyan, A. Dose Response and Optical Properties of Dyed Poly Vinyl Alcohol-Trichloroacetic Acid Polymeric Blends Irradiated with Gamma-Rays. Am. J. Appl. Sci. 2009, 6, 2071-2077. [CrossRef]

30. Dhara, B.; Sappati, S.; Singh, S.K.; Kurungot, S.; Ghosh, P.; Ballav, N. Coordination Polymers of Fe(III) and Al(III) Ions with TCA Ligand: Distinctive Fluorescence, $\mathrm{CO}_{2}$ Uptake, Redox-Activity and Oxygen Evolution Reaction. Dalton Trans. 2016, 45, 6901-6908. [CrossRef]

31. Susilawati, S.; Prayogi, S.; Arif, M.F.; Ismail, N.M.; Bilad, M.R.; Asy'ari, M. Optical Properties and Conductivity of PVA-H3PO4 (Polyvinyl Alcohol-Phosphoric Acid) Film Blend Irradiated by $\gamma$-Rays. Polymers 2021, 13, 1065. [CrossRef]

32. Skuja, L.; Kajihara, K.; Ikuta, Y.; Hirano, M.; Hosono, H. Urbach Absorption Edge of Silica: Reduction of Glassy Disorder by Fluorine Doping. J. Non-Cryst. Solids 2004, 345-346, 328-331. [CrossRef]

33. Mott, N.F.; Davis, E.A. Electronic Processes in Non-Crystalline Materials, 2nd ed.; International Series of Monographs on Physics; Clarendon Press: Oxford, UK, 2012; ISBN 978-0-19-964533-6.

34. Aldweri, F.M.; Rabaeh, K.A.; Al-Ahmad, K.N. Novel Radiochromic Dosimeters Based on Calcein Dye for High Dose Applications. Radiat. Phys. Chem. 2017, 139, 1-4. [CrossRef]

35. Rabaeh, K.A.; Basfar, A.A. A Polystyrene Film Dosimeter Containing Dithizone Dye for High Dose Applications of Gamma-Ray Source. Radiat. Phys. Chem. 2020, 170, 108646. [CrossRef]

36. Aldweri, F.M.; Abuzayed, M.H.; Al-Ajaleen, M.S.; Rabaeh, K.A. Characterization of Thymol Blue Radiochromic Dosimeters for High Dose Applications. Results Phys. 2018, 8, 1001-1005. [CrossRef]

37. Saion, E.; Susilawati; Doyan, A.; Zainal Abidin, S.; Azmi, Z.; Zulkfli, A.; Zaki, A.R.M.; Dahlan, K.Z.H.; Karni, T. Changes in the Optical Band Gap and Absorption Edge of Gamma-Irradiated Polymer Blends. J. Appl. Sci. 2005, 5, 1825-1829. [CrossRef]

38. Abdel-Fattah, A.A.; Abdel-Hamid, H.M.; Radwan, R.M. Changes in the Optical Energy Gap and ESR Spectra of Proton-Irradiated Unplasticized PVC Copolymer and Its Possible Use in Radiation Dosimetry. Nucl. Instrum. Methods Phys. Res. Sect. B Beam Interact. Mater. At. 2002, 196, 279-285. [CrossRef]

39. Ali, H.E.; Abdel-Aziz, M.M.; Algarni, H.; Yahia, I.S. The Structure Analysis and Optical Performance of PVA Films Doped with Fe3+-Metal for UV- Limiter, and Optoelectronics. Mater. Res. Express 2019, 6, 085334. [CrossRef] 
40. Salah, M.; Gad, M.; Elkattan, M.; Sabry, Y.M. Effect of Gamma-Irradiation and Doping on the Absorption Edge and the Optical Bandgap of Silver-Doped PVA Films. Opt. Commun. 2020, 473, 125933. [CrossRef]

41. Otero, T.F.; Martinez, J.G. Activation Energy for Polypyrrole Oxidation: Film Thickness Influence. J. Solid State Electrochem. 2011, 15, 1169-1178. [CrossRef]

42. Singh, S.; Neerja. The Effect of Gamma-Irradiation on the Activation Energy of Bulk and Track Etching in CR-39 Plastic Track Detector. Radiat. Meas. 2007, 42, 1507-1509. [CrossRef]

43. Isac, J. Optical Band Gap Analysis of Nano-Crystalline Ceramic PbSrCaCuO. JAP 2014, 5, 816-822. [CrossRef]

44. Aziz, S.B.; Brza, M.A.; Nofal, M.M.; Abdulwahid, R.T.; Hussen, S.A.; Hussein, A.M.; Karim, W.O. A Comprehensive Review on Optical Properties of Polymer Electrolytes and Composites. Materials 2020, 13, 3675. [CrossRef]

45. Costa, J.C.S.; Taveira, R.J.S.; Lima, C.F.R.A.C.; Mendes, A.; Santos, L.M.N.B.F. Optical Band Gaps of Organic Semiconductor Materials. Opt. Mater. 2016, 58, 51-60. [CrossRef]

46. Escobedo-Morales, A.; Ruiz-López, I.I.; Ruiz-Peralta, M.d.L.; Tepech-Carrillo, L.; Sánchez-Cantú, M.; Moreno-Orea, J.E. Automated Method for the Determination of the Band Gap Energy of Pure and Mixed Powder Samples Using Diffuse Reflectance Spectroscopy. Heliyon 2019, 5, e01505. [CrossRef] [PubMed]

47. Meftah, A.; Gharibshahi, E.; Soltani, N.; Yunus, W.; Saion, E. Structural, Optical and Electrical Properties of PVA/PANI/Nickel Nanocomposites Synthesized by Gamma Radiolytic Method. Polymers 2014, 6, 2435-2450. [CrossRef]

48. Arshak, K.; Korostynska, O. Gamma Radiation Dosimetry Using Tellurium Dioxide Thin Film Structures. Sensors 2002, 2, 347-355. [CrossRef]

49. Talebi, M.; Zahedifar, M.; Sadeghi, E. UVC Dosimetry Properties of Mn and Ce Doped KCl Thermoluminescent Phosphor Produced by Co-Precipitation Method. Nucl. Instrum. Methods Phys. Res. Sect. B Beam Interact. Mater. At. 2019, 458, 97-104. [CrossRef]

50. Horowitz, Y.S. Theory of Thermoluminescence Gamma Dose Response: The Unified Interaction Model. Nucl. Instrum. Methods Phys. Res. Sect. B Beam Interact. Mater. At. 2001, 184, 68-84. [CrossRef] 